\title{
Do manure-borne or indigenous soil microorganisms influence the spread of antibiotic resistance genes in manured soil?
}

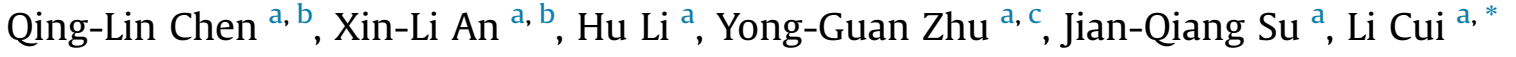 \\ a Key Laboratory of Urban Environment and Health, Institute of Urban Environment, Chinese Academy of Sciences, 1799 Jimei Road, Xiamen 361021, China \\ ${ }^{\mathrm{b}}$ University of Chinese Academy of Sciences, 19A Yuquan Road, Beijing 100049, China \\ c State Key Laboratory of Urban and Regional Ecology, Research Center for Eco-Environmental Sciences, Chinese Academy of Sciences, Beijing 100085, China
}

\section{A R T I C L E I N F O}

\section{Article history:}

Received 12 January 2017

Received in revised form 18 July 2017

Accepted 23 July 2017

Available online 29 July 2017

\section{Keywords:}

Antibiotic resistance genes

Spread and fate

Manure-borne microorganisms

Manured soil

HT-qPCR

\begin{abstract}
A B S T R A C T
Manure application is a common practice that not only adds nutrients and organic matter to arable soils for crop growth, but also introduces antibiotic resistance genes (ARGs), posing a potential risk to human health. To investigate the mechanisms underlying the spread of ARGs in manured soil, especially the impact of manure-borne and indigenous soil microorganisms, a microcosm experiment with four specially designed treatments over a period of two months was conducted, including soil, soil with irradiated pig manure, irradiated soil with pig manure, and soil with pig manure. A total of 240 unique ARGs were detected via a high-throughput quantitative PCR (HT-qPCR) targeting almost all major classes of ARGs. Manure application significantly increased the diversity and abundance of ARGs in soil $(P<0.01)$, and also markedly shifted the bacterial composition that was significantly correlated with ARGs profiles. Manure-borne microorganisms contributed largely to the elevation of ARGs due to both the addition of manure-borne antibiotic resistant bacteria (ARB) in soil and potential horizontal gene transfer (HGT) via mobile genetic elements (MGEs) from manure-borne ARB to indigenous soil microorganisms. In contrast, indigenous soil microorganisms were demonstrated to prevent the dissemination of ARGs from manure to soil. The reason could be due to that indigenous soil microorganisms prevented the invasion and establishment of manure-borne ARB in soil. The abundance of ARG in manured soil decreased over time, but was still higher than that in control soil, indicating the persistence of ARGs in manured soil. These findings may shed light on the mechanisms underlying the spread and fate of ARGs in manured soil and also clues for ARGs mitigation.
\end{abstract}

(C) 2017 Elsevier Ltd. All rights reserved.

\section{Introduction}

Antibiotic resistance genes (ARGs) that occur in the environments such as soils are currently regarded as a serious global health concern (Pruden et al., 2006; Bush et al., 2011), because ARGs can be transmitted and shared between environmental bacteria and human pathogens (Forsberg et al., 2012). In addition, once ARGs are acquired by environmental bacteria, the probability of their maintenance in natural ecosystems is high, even without a high loading of antibiotics (Pallecchi et al., 2008). However, the mechanisms underlying the spread and fate of ARGs in environment are still not clear.

In recent years there has been increasing concern regarding

\footnotetext{
* Corresponding author.

E-mail address: Icui@iue.ac.cn (L. Cui).
}

ARGs in soils because soil is a receptor of released antibiotics and ARGs (Kemper, 2008), especially after anthropogenic activities such as manure application. Land application of animal manures is a common practice in agriculture and is regarded as a cost-saving and efficient way to recycle nutrients from animal wastes (Binh et al., 2008; Chee-Sanford et al., 2009). However, antibiotics are commonly used in concentrated animal feeding operations worldwide to treat animal diseases and promote animal growth (Sarmah et al., 2006; Karci and Balcioglu, 2009). The produced manures have been identified as reservoirs of high levels of antibiotics, heavy metals, antibiotic resistant bacteria (ARB), antibiotic resistant genes (ARGs), and mobile genetic elements (MGEs) (Binh et al., 2008; Pakpour et al., 2012; Zhu et al., 2013). Manure application has also been demonstrated to increases the occurrence and spread of ARGs in soils (Binh et al., 2008; Zhu et al., 2013; Chen et al., 2016). By using high-capacity quantitative PCR arrays, 149 unique resistance genes were detected, and the top 63 ARGs being 
enriched in soil amend with manure (Zhu et al., 2013). Furthermore, ARGs in soil have been demonstrated to be able to enter food chain and even act as potential source of ARGs in human pathogens (Forsberg et al., 2012) via contaminated crops or groundwater, and consequently impact human health (Koike et al., 2007; Marti et al., 2013; Zhu et al., 2017). In contrast to the concern that manure application enhanced the level of ARGs in soil, other studies focused on how to reduce the potential risk of ARGs and found that increases in ARG abundance following manure application was not maintained long-term, but decayed with time ranging from tens of days to six months (Fahrenfeld et al., 2014). Another study reported that a period of delay (such as 15 months) between sewage sludge application and crop harvest was sufficient to attenuate these organic fertilizer-borne ARGs (Rahube et al., 2014). To mitigate the potential risk of manure application, it is important to understand the processes and mechanisms affecting the acquisition and spread of ARGs in soils after manure application.

The increase of ARG levels in manured soils could be related to the considerable amount of resistant bacteria in manure, which can lead to a direct increase in ARGs after manure application (Jiang et al., 2002). Previous studies stated that shifts in microbial communities caused by organic fertilizer amendment (Zhen et al., 2014) can affect the occurrence and abundance of ARGs, and bacterial taxa were found to significantly correlate with the profile of ARGs by network analysis (Chen et al., 2016; Li et al., 2015). The ability of manure-borne microorganisms to adapt to and establish in the soil environment is likely a very important factor for the persistence and spread of ARGs. This depends on many factors, such as the different physicochemical properties between manure and soil, and the competitive or cooperative interaction between manure-borne and indigenous soil microorganisms. It has been reported that the ability of a microbial community to resist invasion by invading species is related to the diversity of the indigenous species (Kennedy et al., 2002; Wertz et al., 2006; van Elsas et al., 2007). Another study also suggested a negative correlation between the diversity of soil microorganisms and the survival of the invader, due to the competition for limiting resources (van Elsas et al., 2012). However, how such interactions between manure-borne and indigenous soil microorganisms affect the occurrence and abundance of ARGs in manured soils remains poorly understood. A comprehensive understanding of this impact is required and will benefit the development of strategies to mitigate the spread of ARGs from animal manures to agricultural soils.

To address the question of how manure-borne and indigenous soil microbial communities affect the spread and fate of ARGs in manured soil, a microcosm experiment with four treatments was conducted in the present work over a period of two months (Kyselková et al., 2015). The four treatments included soil without manure addition (Soil) used as control, soil with $\gamma$-irradiated pig manure (Soil $+\mathrm{RM}), \gamma$-irradiated soil with pig manure $(\mathrm{RS}+\mathrm{M})$, and soil with pig manure (Soil $+\mathrm{M})$. By using a high-throughput quantitative PCR (HT-qPCR) including 296 validated primer sets targeting almost all major classes of ARGs and Illumina sequencing, we evaluated the abundance and diversity of ARG in manured soil, the impact of manure-borne and indigenous soil microorganisms on the spread of ARG, and the temporal change of ARGs after manure application.

\section{Materials and methods}

\subsection{Sampling of soil and collection of pig manure}

Surface soil $(0-20 \mathrm{~cm})$ was collected from a cropland used for planting rice in Jiaxing, Zhejiang, south China $\left(30^{\circ} 50^{\prime} 7.7^{\prime \prime} \mathrm{N}\right.$, $120^{\circ} 43^{\prime} 5.7^{\prime \prime}$ E) in August 2015. The soil parent material was lacustrine deposits and the soil was free from manure applications for approximately ten years. Soil was air dried for 7 days, sieved $(<2 \mathrm{~mm})$, and then kept in a dark place at room temperature until use. Pig manure was obtained in August 2015, from a local commercial pig farm with a history of antibiotic use including tetracycline, macrolide lincosamide streptogramin B (MLSB), and sulfonamides. The manure was air dried for three days at room temperature and sieved $(<2 \mathrm{~mm})$. For the manure, bacterial population was $3.34 \times 10^{13}$ copies per gram solid; the absolute abundance of ARGs was $6.79 \times 10^{13}$ copies per gram solid; the normalized abundance of ARG was 2.03 copies per 16S rRNA genes. Detailed properties of soil and manure are listed in Table S1. Around 6 and $0.8 \mathrm{~kg}$ of soil and manure were treated by $\gamma$-irradiation ( $25 \mathrm{kGy}$ ) with a ${ }^{60} \mathrm{Co}$ source in order to prepare the treatments used in the following microcosm experiments (Wertz et al., 2006; van Elsas et al., 2012; Philippot et al., 2013). We used a plate count procedure to determine if the irradiation had efficiently killed the indigenous bacteria (Yan et al., 2017). Briefly, $0.5 \mathrm{~g}$ of soil and manure was spread onto trypticase soy and potato dextrose agar plate respectively. No bacterial or fungal growth was detected on agar plates after 6 days of incubation at $37{ }^{\circ} \mathrm{C}$. In addition, we estimated the number of PCR templates that could be detected in irradiated samples. Briefly, DNA was extracted from the irradiated soil and manure, and a SYBR ${ }^{\circledR}$ Green approach (Roche 480, Roche Inc., USA) was used to estimate the number of possible residual PCR templates in the irradiated samples (Ouyang et al., 2015). The number of $16 \mathrm{~S}$ rRNA gene copies per gram detected in irradiated soil $\left(2.37 \times 10^{5}\right)$ and manure $\left(1.46 \times 10^{6}\right)$ was seven orders of magnitude lower than that in non-irradiated soil $\left(4.47 \times 10^{12}\right)$ and manure $\left(3.34 \times 10^{13}\right)$.

\subsection{Microcosm experiment}

Before amendment with manure, the air-dried soil was adjusted to $60 \%$ of water-holding capacity (WHC) using autoclaved deionized water and pre-incubated in the dark at $25^{\circ} \mathrm{C}$ for two weeks to recover the microbial activity (Chen et al., 2015; Liu et al., 2016). After the soil pre-incubation, soil microcosms were set up in plastic boxes (radius $15 \mathrm{~cm}$, height $5 \mathrm{~cm}$ ) covered with parafilm to allow air access but reduce loss of moisture. Four treatments were prepared at the beginning with the equivalent of $300 \mathrm{~g}$ dry soil and different amendments, i.e., control (Soil) containing soil only; treatment (Soil $+\mathrm{RM}$ ) containing soil and $15 \mathrm{~g}$ irradiated dry pig manure; treatment $(\mathrm{RS}+\mathrm{M})$ containing irradiated soil and 15 g dry pig manure; and treatment (Soil $+\mathrm{M}$ ) containing soil and $15 \mathrm{~g}$ pig manure. The manure application ratio used in the present study corresponds roughly to a typical agricultural rate of $40 \mathrm{~m}^{3}$ manure $\mathrm{ha}^{-1}$. A total of 15 replicates were prepared for each treatment and used for destructive harvesting at five time points, so three replicates were collected for each time point. Soils were thoroughly mixed with manure and water content was adjusted to $60 \%$ of WHC using autoclaved deionized water. Incubations were performed at $25{ }^{\circ} \mathrm{C}$ in the dark and autoclaved deionized water was supplemented every two days to maintain their water content. Three replicates from each treatment were sampled immediately after mixing (day 0 ) and also after the following incubation time (day 10 , 20,30 and 60). The collected samples were then stored at $-80^{\circ} \mathrm{C}$ before DNA extraction.

\subsection{DNA extraction}

DNA was extracted from $0.5 \mathrm{~g}$ soil with a FastDNA Spin Kit for soil (MP Biomedical, Illkirch, France) according to the manufacturer's instructions. The quality of extracted DNA was analyzed with a spectrophotometer (Nanodrop ND-1000, Thermo Scientific, 
Waltham, MA) and the concentration of DNA was determined using QuantiFluor ${ }^{\circledR}$ dsDNA system (Promega, Madison, WI) based on fluorometric analysis with a microplate reader (Spectramax M5, Molecular Devices, Sunnyvale, CA). The total DNA was stored at $-20^{\circ} \mathrm{C}$ until use.

\subsection{High-throughput quantitative $P C R$}

To evaluate the abundance and diversity of ARGs in samples, HTqPCR of ARGs was performed using the Wafergen SmartChip Realtime PCR system (Wafergen, Fremont, CA). This SmartChip platform can be used for large-scale gene expression analysis by processing 5184-nanowell reactions per run. DNA template was diluted to $50 \mathrm{ng} / \mu \mathrm{L}$ and finally standardized to $5 \mathrm{ng} / \mu \mathrm{L}$ in $100 \mathrm{~nL}$ PCR mixtures per well consisting of $1 \times$ LightCycler 480 SYBR Green I Master (Roche Applied Sciences, Indianapolis, IN), nuclease-free PCR-grade water, $1 \mathrm{ng} / \mu \mathrm{L}$ bovine serum albumin (New England Biolaboratories, Beverly, MA), $500 \mathrm{nM}$ each primer and $5 \mathrm{ng} / \mu \mathrm{L}$ DNA template. The 296 primer sets targeting 285 ARGs, 8 transposases, 1 class1 integrase, 1 clinic integrase and 16S rRNA gene have been validated and used in previous studies (Zhu et al., 2013; Chen et al., 2016). Amplification for each primer set was conducted in triplicate with an additional non-template control by performing an initial denaturation at $95{ }^{\circ} \mathrm{C}$ for $10 \mathrm{~min}$, followed by 40 cycles of denaturation at $95^{\circ} \mathrm{C}$ for $30 \mathrm{~s}$ and annealing at $60^{\circ} \mathrm{C}$ for $30 \mathrm{~s}$. A melting curve analysis was finally auto-generated by SmartChip qPCR software (V 2.7.0.1). The wells with multiple melting peaks and those with amplification efficiency beyond the range (1.8-2.2) were discarded. A threshold cycle $\left(C_{T}\right)$ of 31 was used as the detection limit, and only ARGs with amplification in all replicates were regarded as positive ones. Relative copy number was calculated according to Eq. (1) (Chen et al., 2016) and the relative copy numbers were transformed to absolute copy numbers by normalizing to 16S rRNA gene copy numbers which was quantified separately from the Wafergen platform. To minimize potential variations in DNA extraction and analytical efficiencies as well as background bacterial abundances, the abundance of ARGs was normalized by $16 \mathrm{~S}$ rRNA gene and represented as ARG copies/16S rRNA gene. In previous studies, the abundance of ARGs was normalized by bacterial cell numbers, i.e., ARG copies/bacterial cell (Su et al., 2015; Chen et al., 2017) based on the average of 4.1 copies of 16S rRNA gene per bacterium (Klappenbach et al., 2001). However, gene copies can vary widely in different bacteria from 1 to up to 15 (Kembel et al., 2012); while only limited number of active species may dominate under tense competition situation in soil. Therefore, ARG copies/bacterial cell may induce over or under estimation of normalized ARGs abundance. To avoid this problem, in the present study, we used ARG copies/16S rRNA gene as the normalized abundance of ARGs. A comparative $C_{T}$ method (Eq. (2)) was used to calculate the fold change of each ARG (FC value) in treatments compared to the control (Schmittgen and Livak, 2008). The detection limit $C_{T}$ (31) was taken as a replacement for the genes with no amplification. HT-qPCR reactions were performed using a series of diluted plasmid as positive control with a minimum concentration of 1 copy per well (100 nL per well). The result showed that the average $\mathrm{Ct}$ was about 31 at this minimum concentration, and thus a threshold value of 31 was used in the present study. The corresponding detection limit was 100 copies target genes/ $\mu \mathrm{L}$, corresponding to 2 copies/ng DNA.

Relative gene copy number $=10^{\left(31-C_{\mathrm{T}}\right) /(10 / 3)}$

$\Delta \mathrm{C}_{\mathrm{T}}=\mathrm{C}_{\mathrm{T}(\mathrm{ARG})} \mathrm{\partial}-\mathrm{C}_{\mathrm{T}(16 \mathrm{~S})}$
$\Delta \Delta \mathrm{C}_{\mathrm{T}}=\Delta \mathrm{C}_{\mathrm{T}(\text { Treatment })}-\Delta \mathrm{C}_{\mathrm{T}(\text { Control })}$

$\mathrm{FC}=2^{\left(-\Delta \Delta \mathrm{C}_{\mathrm{T}}\right)}$

\subsection{S rRNA gene amplification, Illumina sequencing, and data processing}

Bacterial 16S rRNA (V4-V5 region) was amplified using primers F515: GTGCCAGCMGCCGCGG and R907: CCGTCAATTCMTTTRAGTTT (Chen et al., 2016). In order to pool all samples, the reverse primer was tagged with unique barcode for each sample (Rastogi et al., 2012). After initial enzyme activation at $95{ }^{\circ} \mathrm{C}$ for $5 \mathrm{~min}, 30$ cycles of the following program were used for amplification: $95{ }^{\circ} \mathrm{C}$ for $30 \mathrm{~s}, 58^{\circ} \mathrm{C}$ for $30 \mathrm{~s}$ and $72^{\circ} \mathrm{C}$ for $30 \mathrm{~s}$. Three replications of $50 \mu \mathrm{l}-\mathrm{PCR}$ mixture were conducted for each sample. Amplicons were purified using a TIANGEN universal DNA purification kit (TIANGEN Biotech, Beijing, China). The PCR products were quantified, pooled at equal concentrations and submitted for sequencing using Illumina Hiseq2500 platform (Novogene, Beijing, China). To guarantee the quality of downstream analysis, raw pair-end reads were filtered to discard raw reads containing three or more ambiguous nucleotides, or with a low $(<20)$ average quality score, or with a short (<100 nt) length, and barcode to generate clean joined reads capturing the complete V4-V5 region of the 16S rRNA gene by Novogene. The generated high quality sequences were processed and analyzed using QIIME with the default parameters for each step (Caporaso et al., 2010). The operational taxonomic unit (OTU) picking was performed following the open-reference online instruction of QIIME. Taxonomic classification and quantification of OTUs were performed against the Greengenes version 13.5 16S rRNA database (McDonald et al., 2012; Langille et al., 2013). Chimeric sequences, chloroplast and mitochondrial OTUs (around 1\%), and singleton OTUs were discarded from the final OTU table. To deal with unequal sampling depth, the sequences were subsampled at the same sequence depth (Xie et al., 2015). OTUs were defined at the $97 \%$ similarity level using UCLUST clustering (Edgar, 2010).

\subsection{Statistical analysis}

Alpha-diversity of bacterial communities was described for each sample using the metrics Chao1 and Observed species (Hartmann and Widmer, 2006). Significant differences in specific taxa between treatments were identified by linear discriminant analysis (LDA) effect size (LEfSe: http://huttenhower.sph.harvard.edu/ galaxy/) (Segata et al., 2011). The threshold on the logarithmic LDA score for discriminative features was set at 2.0 and $\alpha=0.01$ (Taft et al., 2014), and features with at least 2.0 log-fold changes were considered significant. LEfSe detects differentially distributed lineages with the Kruskall-Wallis test, and then checks the consistency of subclass distinctions with the pairwise Wilcoxon text. The final linear discriminant analysis was used to rank all differentiating lineages by their effect size (McKenney et al., 2015). Betadiversity of microbial communities and ARG was compared using the Bray-Curtis distances followed by principal coordinate analysis (PCoA) and Adonis test (Su et al., 2015). Mantel test was used to correlate microbial communities with the profile of ARG. Heatmap was used to show the normalized abundance of ARG. PCoA, Adonis test, mantel test, and heatmap were performed in $\mathrm{R}$ with vegan and pheatmap packages (Kolde, 2013; Oksanen et al., 2014; RCoreTeam, 2014). Cytoscape (V3.2.1) was used to construct the network based on the Spearman correlation matrix (Shannon et al., 2003). All statistical tests using one-way ANOVA (LSD) test performed by SPSS Software V20.0 (IBM, USA) and considered significant at $P<0.05$. 


\section{Results}

\subsection{Diversity, abundance and enrichment of ARGs}

A total of 240 ARGs were detected among all the treatments during the incubation period. Treatment RS + M harbored the most diverse ARGs with an average number of detected ARGs of $159 \pm 14$, followed by treatments Soil $+\mathrm{M}(132 \pm 41)$ and Soil $+\mathrm{RM}$ $(112 \pm 16)$. The control harbored the least ARGs with a total of $98 \pm 23$ ARGs (Fig. 1A). In addition, the application of non-irradiated manure, including treatments of RS $+M$ and Soil $+M$, significantly increased the abundance of ARGs $(P<0.01)$ (Fig. 1B) by 47.45 $(\mathrm{RS}+\mathrm{M})$ and 20.97 times (Soil $+\mathrm{M}$ ) respectively compared with the unamended soil. By comparison, the application of irradiated manure (Soil + RM) did not exhibit significant increase in ARG abundance $(P>0.05)$. Interestingly, ARG abundance in RS $+\mathrm{M}$ was approximately 2.72 -fold higher than that in Soil $+M$. With the increase of incubation time, ARG abundance in both treatments of $\mathrm{RS}+\mathrm{M}$ and Soil + M decreased (Fig. 1B), but was still much higher than that in control Soil $(P<0.01)$. No obvious difference of bacterial abundance can be observed in control Soil and Soil + RM. In contrast, the application of non-irradiated manure induced a significant increase of bacterial abundance $(P<0.01)$ (Fig. 1C). With the increase of incubation time, bacterial abundance in treatment of Soil + M decreased after day 10 .

ARGs were classified into nine types based on the classes of antibiotics that they resisted, i.e., aminoglycoside, beta-lactams, chloramphenicol, MLSB, multidrug, sulfonamide, tetracycline, vancomycin and others. The application of non-irradiated manure (Soil $+\mathrm{M}, \mathrm{RS}+\mathrm{M})$ markedly increased $(P<0.01)$ the resistance genes to aminoglycoside, multidrug, tetracycline, and also MGEs (Fig. 2). Additional increase in resistance genes to chloramphenicol and MLSB was also observed, especially in irradiated soil (RS $+M$ ). In addition, the overall patterns of ARGs were shifted after manure application (Adonis tests, $P<0.001$ ). PCoA analysis based on the Bray-Curtis distance showed that ARGs patterns in the samples from each treatment clustered together and were separated from other treatments (Fig. 3A). The first two principal components axes (PCs) explained a total of $76.56 \%$ of the variance of ARGs. The Soil + M treatment was separated from the control (Soil) mainly along PC1 (explained $62.45 \%$ of variance), whereas Soil + RM was separated from the control along PC2 (explained 14.11\% of variance), indicating that non-irradiated manure (Soil $+\mathrm{M}$ ) caused a larger shift in ARG pattern than irradiated manure (Soil + RM). The $\mathrm{RS}+\mathrm{M}$ treatment caused the largest shift in the ARG profile and was separated from the control along both PC1 and PC2.

Fold change values (FC values), representing the enrichment of ARG compared with the control (i.e., unamended soil) showed that a total of 120 ARGs and MGEs were significantly enriched $(P<0.01)$ in at least one sample. From the heatmap indicative of fold changes (Fig. S1), we observed that many more ARGs were enriched in treatment of RS + M than in Soil + M or Soil + RM. The maximum enrichment of single ARGs (tet X) was up to 17,424-fold in treatment RS + M on day 20. MGEs (including class 1 integron-integrase and transposases) were also enriched with the maximum enrichment of up to 29,044-fold for a single transposase (tnpA-05) in the treatment of RS + M on day 20 .

\subsection{Bacterial community revealed by $16 \mathrm{~S}$ rRNA gene sequencing}

A total of 4,050,694 high-quality sequences were obtained from all samples with sequences per sample ranging from 56,873 to 114,970 . These sequences were clustered into 22,509 OTUs at $3 \%$ dissimilarity level. Rarefaction curves of OTUs at the sequencing depth of 12,000 (Fig. S2) showed that bacterial alpha-diversity decreased significantly after the application of manure at the end of the incubation $(P<0.01)$, which was confirmed by the evaluation of observed species and Chao1 estimator (Fig. 4A). Bacterial communities (beta-diversity) from all the samples during the incubation period were classified into different clusters based on PCOA analysis (Fig. 3B). The first two PCs explained 32.14\% (PC1) and $22.65 \%$ (PC2) of the variance, respectively. The four treatments were separated from each other, revealing a significant shift of the overall bacterial community among the treatments (Adonis test, $P<0.001)$.

Significant differences in specific taxa between treatments were identified by linear discriminant analysis (LDA) effect size (LEfSe). A total of 107 bacterial taxa were differentially enriched $(\alpha<0.01$, LDA score $>2.0$ ) in the four treatments (Fig. S3). To better visualize the shifts in bacterial community, LDA was displayed in cladograms (Fig. 4B). It can be clearly observed that Actinobacteria was markedly enriched in the treatment of Soil + M. Sphingobacteriia (j) phylum of Bacteroidetes and Clostridia (q) phylum of Firmicutes were enriched in RS + M. Saprospirae (h), phylum of Bacteroidetes and Planctomycetia (u) phylum of Gemmatimonadetes were enriched in Soil + RM.

\subsection{Correlation between ARGs and bacterial community}

A mantel test showed that the profile of ARGs was significantly correlated to bacterial compositions and structures based on BrayCurtis distance $(r=0.5088, P=0.0001)$. The correlation between ARGs and bacterial taxa was further explored using network analysis (Fig. 5) aiming to determine if the abundance of resistance genes was correlated with specific phylogenetic groups. The topological properties widely used in network analysis were provided in
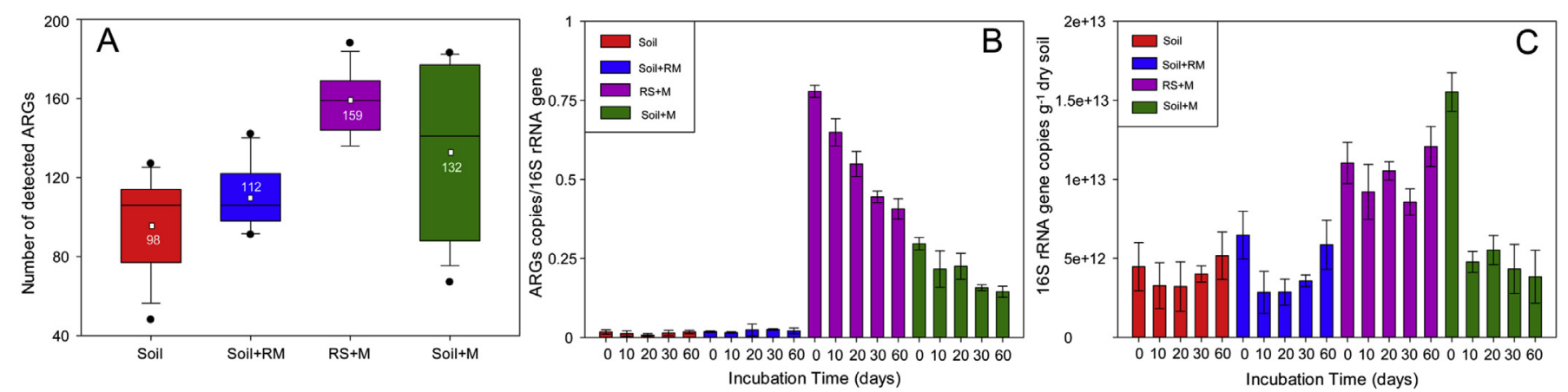

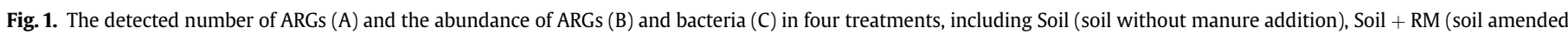
with irradiated pig manure), RS + M (irradiated soil amended with pig manure), and Soil + M (soil amended with pig manure). 


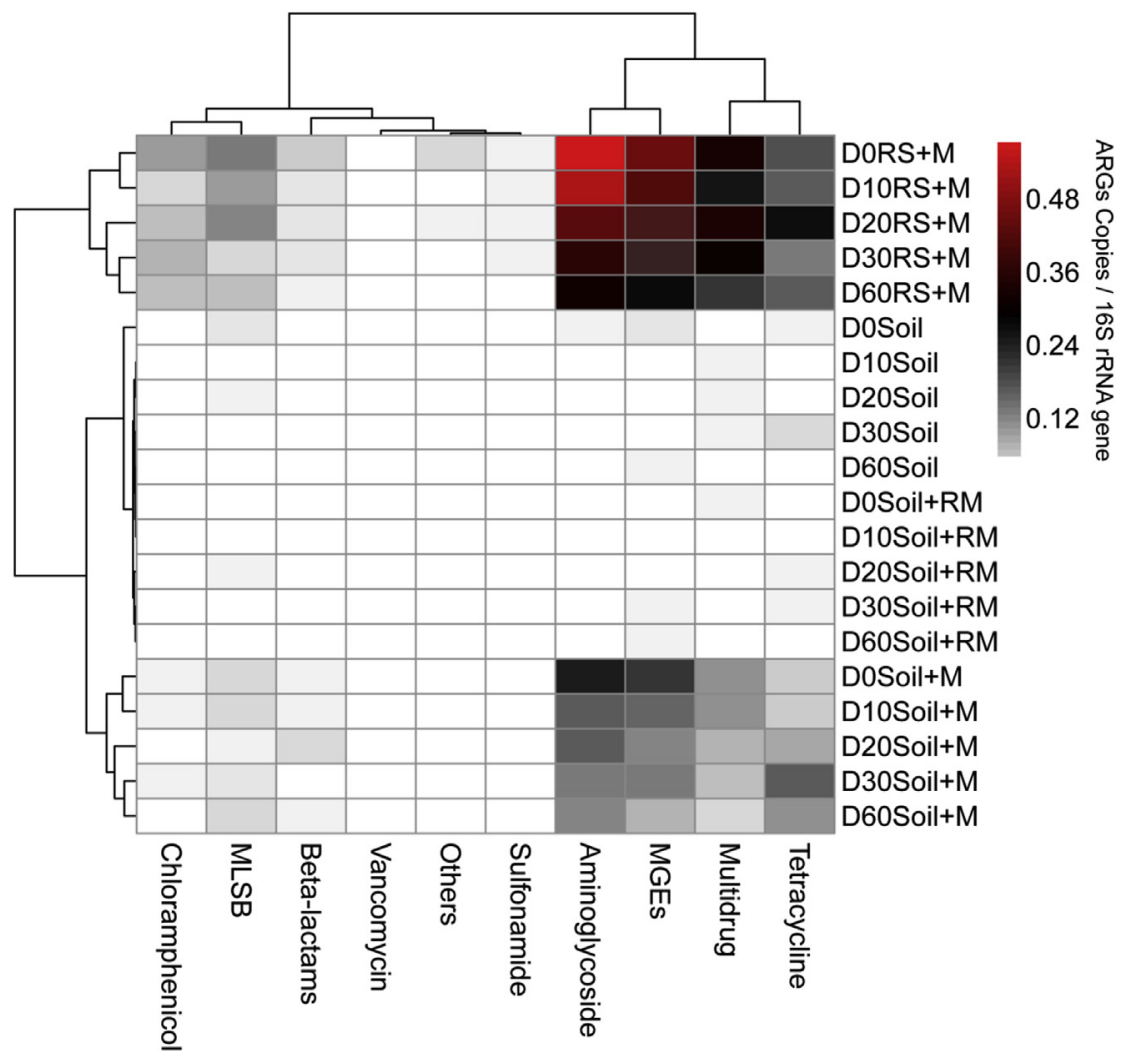

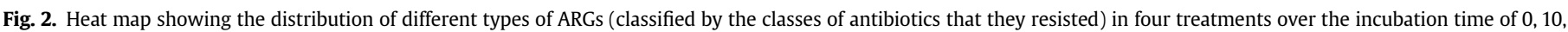
20, 30 and 60 days (D0, D10, D20, D30, D60).
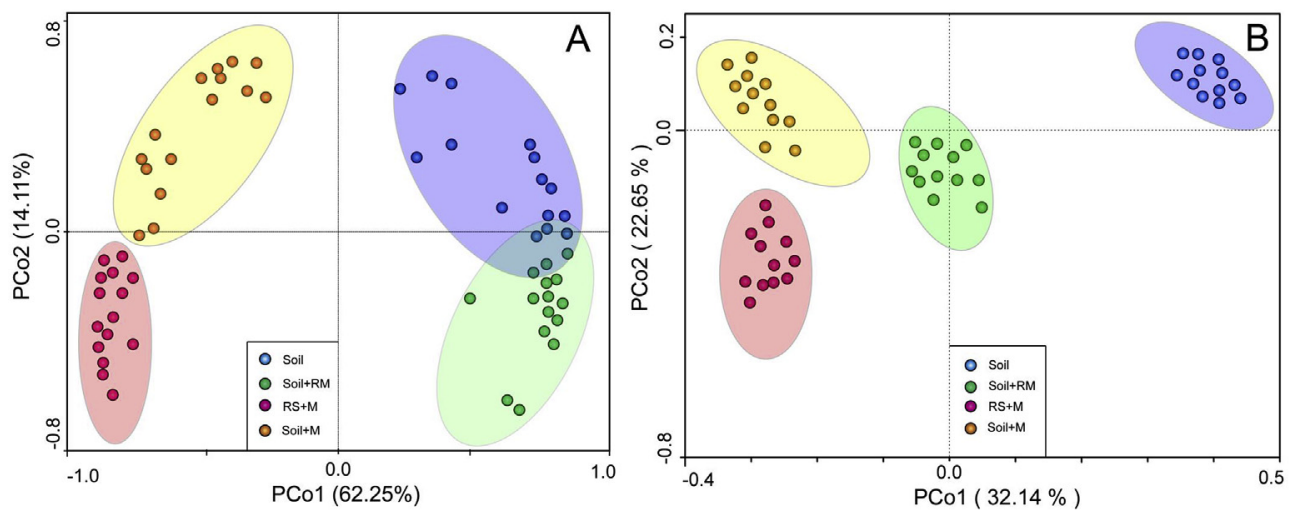

Fig. 3. Principal coordinate analysis (PCoA) based on the Bray-Curtis distance showing the overall distribution pattern of ARGs (A) and bacterial communities (B).

Table S2. A total of 25 bacterial taxa were identified to have a strong and significant positive correlation with ARGs (Fig. 5). In the control (Soil), Isosphaeraceae was positively correlated with ARGs ( $\rho>0.8$, $P<0.01$ ) conferring resistance to beta-lactams (ampC-04, blaSHV01, blaCMY2-02), MLSB [erm(36)] and multidrug (acrA-04, acrA-05, mtrD-02), while Thermomonosporaceae and Sphingomonadaceae were positively correlated with more diverse ARGs conferring resistance to tetracycline, multidrug, beta-lactams, MLSB, aminoglycoside and a transposases (tnpA-01) (Fig. 5A). In treatment of Soil + RM (Fig. 5B), Thermomonosporaceae and Sphingomonadaceae were positively correlated with floR and blaPSE. By comparison, Peptostreptococcaceae, Streptococcaceae and Christensenellaceae co- occurred with more ARGs. In treatments of RS + M (Fig. 5C) and Soil + M (Fig. 5D), the correlation pattern between bacterial taxa and ARGs was much more complex than that of Soil or Soil + RM, with a single bacterial taxon correlated with different ARGs and a single ARG correlated with diverse bacterial taxa. Network analysis has been widely used to explore the underlying interaction among microbial taxa in complex microbial communities (Ling et al., 2016). Based on the non-random co-occurrence between ARGs and bacterial taxa, this approach might represent an appropriate strategy to track potential ARG hosts (Forsberg et al., 2014; Li et al., 2015). Therefore the 25 bacterial taxa that we identified might be the possible potential hosts harboring ARGs. 


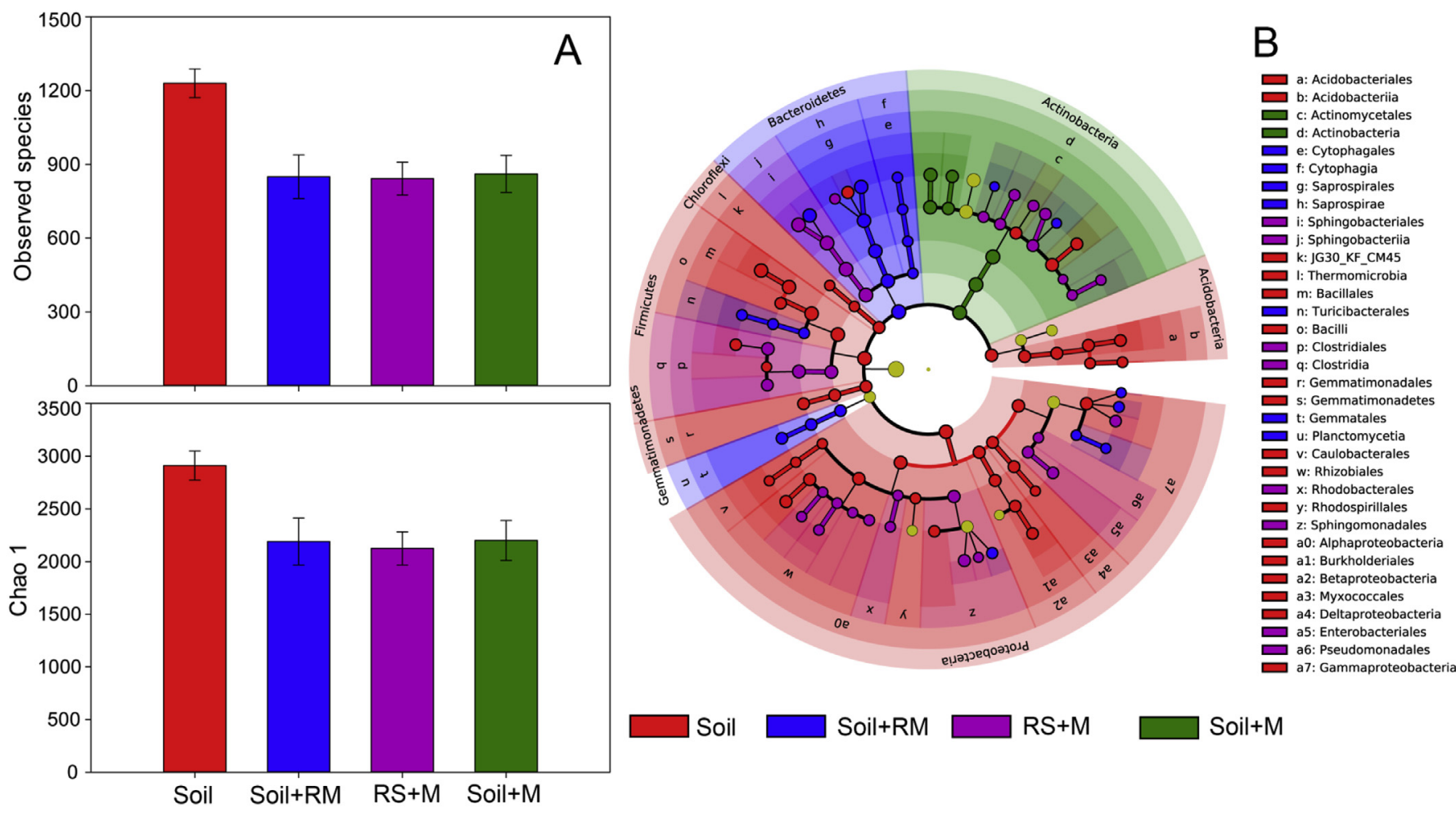

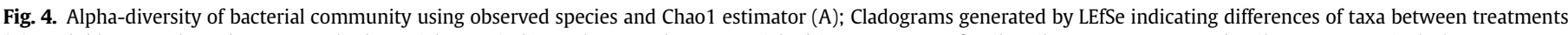

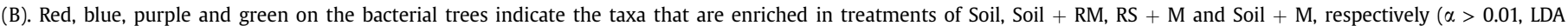
score $>2.0$ ). (For interpretation of the references to colour in this figure legend, the reader is referred to the web version of this article.)

\section{Discussion}

\subsection{Impact of manure application on soil antibiotic resistance genes and bacterial community}

A total of 98 diverse ARGs were detected in the untreated soil. It is not surprising since antibiotic resistance has been well documented to be ancient and can occur naturally (D'Costa et al., 2011), even if various antibiotics had not been produced (Davelos et al., 2004). After manure application, both the abundance and diversity of ARGs increased dramatically (Fig. 1), especially for genes conferring resistance to tetracycline, multidrug aminoglycoside, and MLSB, demonstrating that manure application can cause occurrence and spread of ARGs in soil. These findings are supported by previous reports that manure application caused the spread of ARGs to agricultural fields (Joy et al., 2013; Fahrenfeld et al., 2014; Tang et al., 2015) and that animal manures were the 'hot spots' of ARGs (Binh et al., 2008; Wang et al., 2012). Bacterial abundance after manure application was not observed to increase over the incubation time (Fig. 1C), contrary to what has been reported by previous publications that manure application stimulated microbial growth (Chakraborty et al., 2010; Parham et al., 2003). Factors that possibly resulted in this inconsistent result included variations in chemical properties of manure, such as the content of heavy metals and antibiotics in manure (Table S1), and also different conditions between microcosm and field study. In this study, a high level of antibiotics and heavy metal were detected in manure (Table S1). Despite the fact that application of irradiated manure did not significantly increase the total abundance of ARG $(P>0.05)$, the composition of ARG was significantly altered (Adonis, $P<0.05$ ). Additionally, bacterial composition was significantly correlated with ARGs profiles based on the mantel test $(r=0.5088$,
$\mathrm{P}=0.0001$ ), was consistent with previous studies (Forsberg et al., 2014; Chen et al., 2016). Therefore, antibiotics and heavy metals in manure might pose a selection or co-selection for resistance by shifting the soil microbial compositions (Zhu et al., 2013).

\subsection{Impact of manure-borne microorganisms on the spread of ARGs}

Several mechanisms may be involved in the manure-induced increase in the abundance and diversity of ARGs in soil such as (1) survival and proliferation of fecal microorganisms containing resistance genes in soil (Heuer et al., 2011b); (2) ARG horizontal transfer via MGEs to indigenous soil microorganisms (Fang et al., 2015). In the present study, the abundance and detected number of ARGs in Soil + M were much higher than that of Soil + RM, and this difference is likely due to the absence of manure-borne microorganisms in the treatment of Soil + RM. This assumption is supported by the fact that $16 \mathrm{~S}$ rRNA gene copies decreased dramatically after manure sterilization, and that no bacteria from irradiated manure grew on agar plate. In other words, survival and proliferation of manure-borne microorganisms containing resistance genes played an important part in the occurrence and dissemination of ARGs in manured soil. Previous reports also suggested that manure antibiotic resistant bacteria potentially accounted for ARG persistence in manure-treated soil (CheeSanford et al., 2009).

Horizontal transfer of ARGs from manure to soil bacteria is also a potential pathway for the spread and dissemination of ARGs among different microorganisms (Pruden et al., 2006), since some of the bacteria from manure may not adapt well to the soil environment (Heuer et al., 2011a). In the present study, the enrichment of MGEs, including transposases and class 1 integron-integrase, in manureamended soils compared with control soil suggested that the 

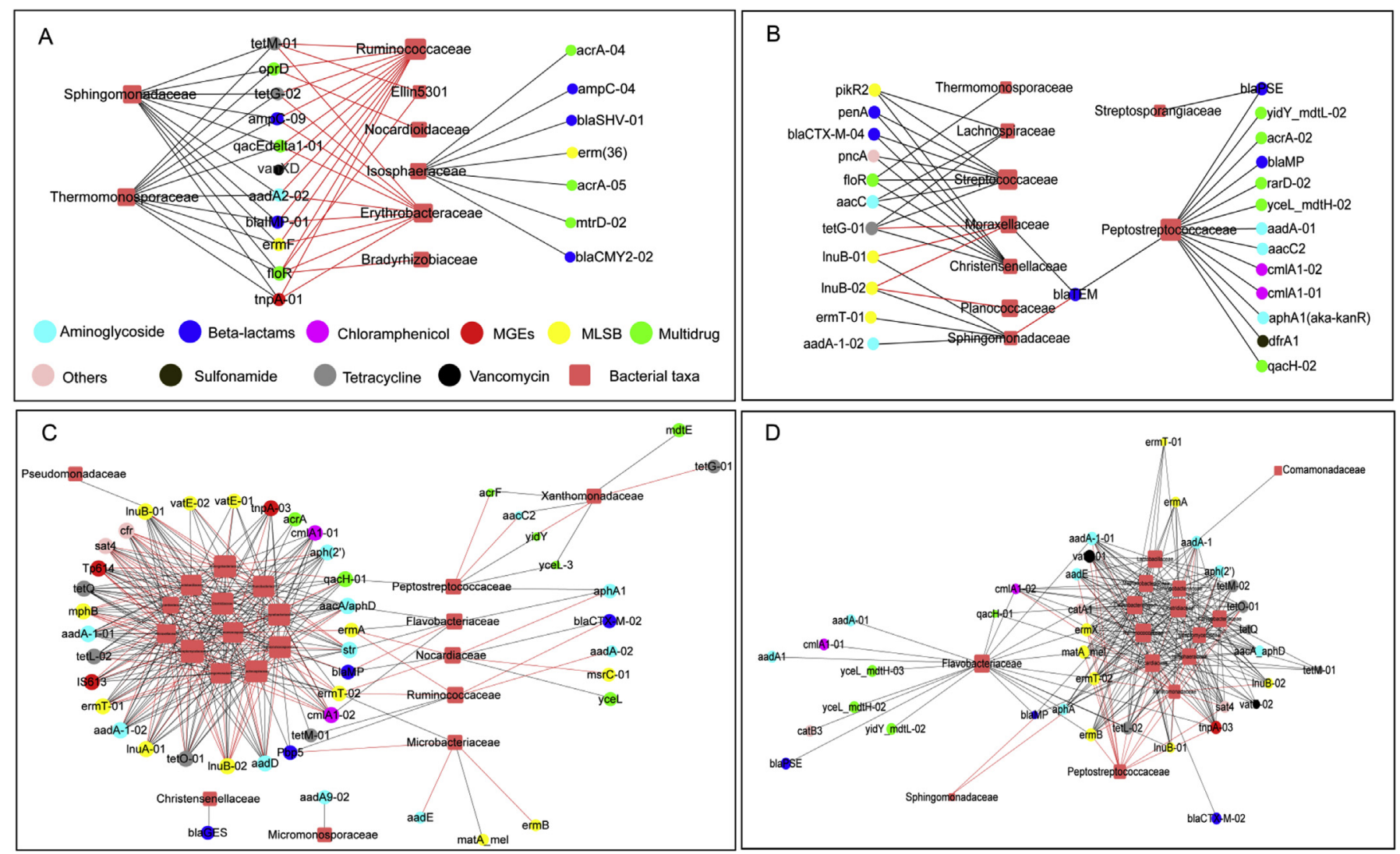

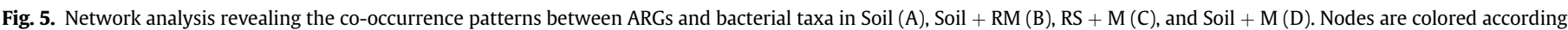

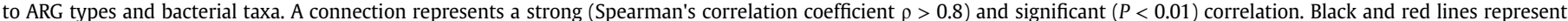

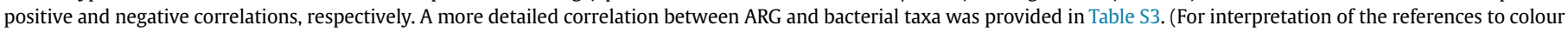
in this figure legend, the reader is referred to the web version of this article.)

application of manure may potentially disseminate ARGs in soil through horizontal gene transfer. Since most of ARG cassettes are found on integrons frequently located on plasmids and transposons (Heuer et al., 2011a), which might be transferred from manure bacteria to indigenous bacteria following manure application (Binh et al., 2008; Allen et al., 2010). It was also suggested that manure application increased the permissiveness of soil community for receiving and maintaining broad-host-range plasmids (Jechalke et al., 2014).

\subsection{Impact of indigenous soil microorganisms on the spread of ARGS}

Another important finding of the present study was the obviously higher abundance of ARGs in RS + M than that in Soil + M (Fig. 1). The difference between them was the absence of viable indigenous soil microorganisms after soil sterilization, indicating that the indigenous soil microbial communities might play an important role in preventing the spread of ARGs in manured soil. Some theoretical and experimental studies have demonstrated that biologically diverse communities were less prone to invasion by alien microorganisms than simpler ones (Case, 1990; Levine, 2000; Kennedy et al., 2002). van Elsas et al. also found a negative correlation between the diversity of indigenous soil microbiota and survival of invader using Escherichia coli 0157:H7 as invader species, and demonstrated that the diversity of indigenous soil microorganisms was a key factor in controlling the extent to which bacterial invaders can establish (van Elsas et al., 2007; van Elsas et al., 2012). In our study, we also observed a lower bacterial abundance in Soil $+M$ than that in RS + M (Fig. 1C), suggesting that indigenous soil microorganisms prevented the establishment of manure-borne microorganism and also the spread of ARGs. The underlying mechanisms may lie in competition for limiting resources (van Elsas et al., 2012) and negative species interactions, such as excretion of inhibiting compounds by indigenous fungi and bacteria. Additionally, predation of manure-borne microorganisms by protozoa and nematodes in soil is also a possible reason for the lower bacterial abundance and ARGs in Soil + M than RS + M (Ronn et al., 2002). Therefore, indigenous soil microorganisms may inhibit the invasion and establishment of manure-borne microorganisms that have been demonstrated to mainly account for ARGs occurrence in manured soil, resulting in a lower ARGs abundance in soil than that in irradiated soil. In the present study we employed two extreme levels of indigenous soil microbial diversity, either full microbial diversity (non-irradiated) or complete absence of indigenous microorganisms (irradiated soils). Further studies employing a dilution-to-extinction approach (Wertz et al., 2007; Philippot et al., 2013) will provide more detailed information regarding the relationship between the spread of ARGs and indigenous soil microbial diversity.

\subsection{The fate of ARGs in manured soil}

Although land application of manure is a common practice in crop production, current knowledge regarding the temporal changes of ARGs following manure amendment is limited, hindering reliable prediction of ARG behaviors in soil environment. In the present study, despite the obvious elevation of ARGs after 
manure application, the abundance of ARGs in manured soil decreased over time. Some previous studies reported a similar phenomenon that the abundance of ARGs in soil did not remain for a long term following manure application (Ghosh and LaPara, 2007; Zhou et al., 2010; Fahrenfeld et al., 2014). The reasons could be related to the different manure and soil environments. For example, growth of some animal gut microbiota under anaerobic conditions (Goodman et al., 2011) can be restricted under the aerobic conditions in our microcosms. In addition, different physiochemical properties (such as water, nutrient content, and $\mathrm{pH}$ ) may also affect the survival of manure-borne microbiota in the soil environment (Drenovsky et al., 2004; Zhalnina et al., 2015). These could result in the loss of fitness of manure-borne microorganism to the soil environment and thus the decrease of ARG abundance with time (Hu et al., 2016). Nevertheless, the abundance of ARG in manured soil was still much higher than that of control soil at the end of incubation, indicating the potential risk of manure application to the dissemination and persistence of ARGs in the soil environment.

In summary, the present study provides insights into the impact of the manure-borne and indigenous soil microorganisms on the dissemination of ARGs. Elimination of manure-born microorganisms can, to a large extent, mitigate the spread of ARGs in manured soil, and a high diversity of indigenous soil microbial community may resist the spread of ARGs from manure to soil. These findings are important for understanding of the spread and fate of ARGs in the environment and also helpful for developing of effective manure and risk management practices to control ARGs contamination.

\section{Conflict of interest}

We declare no conflict of interest.

\section{Acknowledgements}

This work was supported by the National Natural Science Foundation of China $(21210008,41571130063)$, the Knowledge Innovation Program of the Chinese Academy of Sciences IUEQN20150 and the Youth Innovation Promotion Association, CAS (2014266).

\section{Appendix A. Supplementary data}

Supplementary data related to this article can be found at http:// dx.doi.org/10.1016/j.soilbio.2017.07.022.

\section{References}

Allen, H.K., Donato, J., Wang, H.H., Cloud-Hansen, K.A., Davies, J., Handelsman, J., 2010. Call of the wild: antibiotic resistance genes in natural environments. Nature Reviews Microbiology 8, 251-259.

Binh, C.T., Heuer, H., Kaupenjohann, M., Smalla, K., 2008. Piggery manure used for soil fertilization is a reservoir for transferable antibiotic resistance plasmids. FEMS Microbiology Ecology 66, 25-37.

Bush, K., Courvalin, P., Dantas, G., Davies, J., Eisenstein, B., Huovinen, P., Jacoby, G.A., Kishony, R., Kreiswirth, B.N., Kutter, E., Lerner, S.A., Levy, S., Lewis, K., Lomovskaya, O., Miller, J.H., Mobashery, S., Piddock, L.J., Projan, S., Thomas, C.M., Tomasz, A., Tulkens, P.M., Walsh, T.R., Watson, J.D., Witkowski, J., Witte, W., Wright, G., Yeh, P., Zgurskaya, H.I., 2011. Tackling antibiotic resistance. Nature Reviews Microbiology 9, 894-896.

Caporaso, J.G., Kuczynski, J., Stombaugh, J., Bittinger, K., Bushman, F.D., Costello, E.K., Fierer, N., Pena, A.G., Goodrich, J.K., Gordon, J.I., Huttley, G.A., Kelley, S.T., Knights, D., Koenig, J.E., Ley, R.E., Lozupone, C.A., McDonald, D., Muegge, B.D., Pirrung, M., Reeder, J., Sevinsky, J.R., Turnbaugh, P.J., Walters, W.A., Widmann, J., Yatsunenko, T., Zaneveld, J., Knight, R., 2010. QIIME allows analysis of highthroughput community sequencing data. Nature Methods 7, 335-336.

Case, T.J., 1990. Invasion resistance arises in strongly interacting species-rich model competition communities. Proceedings of the National Academy of Sciences of the United States of America 87, 9610-9614.

Chakraborty, A., Chakrabarti, K., Chakraborty, A., Ghosh, S., 2010. Effect of long-term fertilizers and manure application on microbial biomass and microbial activity of a tropical agricultural soil. Biology and Fertility of Soils 47, 227-233.

Chee-Sanford, J.C., Mackie, R.I., Koike, S., Krapac, I.G., Lin, Y.F., Yannarell, A.C. Maxwell, S., Aminov, R.I., 2009. Fate and transport of antibiotic residues and antibiotic resistance genes following land application of manure waste. Journal of Environmental Quality 38, 1086-1108.

Chen, Q.L., An, X.L., Zhu, Y.G., Su, J.Q., Gillings, M.R., Ye, Z.L., Cui, L., 2017. Application of struvite alters the antibiotic resistome in soil, rhizosphere, and phyllosphere. Environment Science Technology 51, 8149-8157.

Chen, Q., An, X., Li, H., Su, J., Ma, Y., Zhu, Y.G., 2016. Long-term field application of sewage sludge increases the abundance of antibiotic resistance genes in soil. Environment International 92-93, 1-10.

Chen, Q., Wang, H., Yang, B., He, F., Han, X., Song, Z., 2015. Responses of soil ammonia-oxidizing microorganisms to repeated exposure of single-walled and multi-walled carbon nanotubes. Science of the Total Environment 505 649-657.

D'Costa, V.M., King, C.E., Kalan, L., Morar, M., Sung, W.W., Schwarz, C., Froese, D. Zazula, G., Calmels, F., Debruyne, R., Golding, G.B., Poinar, H.N., Wright, G.D., 2011. Antibiotic resistance is ancient. Nature 477, 457-461.

Davelos, A.L., Kinkel, L.L., Samac, D.A., 2004. Spatial variation in frequency and intensity of antibiotic interactions among streptomycetes from prairie soil. Applied and Environmental Microbiology 70, 1051-1058.

Drenovsky, R.E., Vo, D., Graham, K.J., Scow, K.M., 2004. Soil water content and organic carbon availability are major determinants of soil microbial community composition. Microbial Ecology 48, 424-430.

Edgar, R.C., 2010. Search and clustering orders of magnitude faster than blast. Bioinformatics 26, 2460-2461.

Fahrenfeld, N., Knowlton, K., Krometis, L.A., Hession, W.C., Xia, K., Lipscomb, E. Libuit, K., Green, B.L., Pruden, A., 2014. Effect of manure application on abundance of antibiotic resistance genes and their attenuation rates in soil: fieldscale mass balance approach. Environmental Science \& Technology 48, 2643-2650.

Fang, H., Wang, H., Cai, L., Yu, Y., 2015. Prevalence of antibiotic resistance genes and bacterial pathogens in long-term manured greenhouse soils as revealed by metagenomic survey. Environmental Science \& Technology 49, 1095-1104.

Forsberg, K.J., Patel, S., Gibson, M.K., Lauber, C.L., Knight, R., Fierer, N., Dantas, G. 2014. Bacterial phylogeny structures soil resistomes across habitats. Nature 509, 612-616.

Forsberg, K.J., Reyes, A., Wang, B., Selleck, E.M., Sommer, M.O.A., Dantas, G., 2012 The shared antibiotic resistome of soil bacteria and human pathogens. Science 337, 1107-1111.

Ghosh, S., LaPara, T.M., 2007. The effects of subtherapeutic antibiotic use in farm animals on the proliferation and persistence of antibiotic resistance among soil bacteria. The ISME Journal 1, 191-203.

Goodman, A.L., Kallstrom, G., Faith, J.J., Reyes, A., Moore, A., Dantas, G., Gordon, J.I. 2011. Extensive personal human gut microbiota culture collections characterized and manipulated in gnotobiotic mice. Proceedings of the National Academy of Sciences of the United States of America 108, 6252-6257.

Hartmann, M., Widmer, F., 2006. Community structure analyses are more sensitive to differences in soil bacterial communities than anonymous diversity indices. Applied and Environmental Microbiology 72, 7804-7812.

Heuer, H., Schmitt, H., Smalla, K., 2011a. Antibiotic resistance gene spread due to manure application on agricultural fields. Current Opinion in Microbiology 14, 236-243.

Heuer, H., Solehati, Q., Zimmerling, U., Kleineidam, K., Schloter, M., Muller, T. Focks, A., Thiele-Bruhn, S., Smalla, K., 2011b. Accumulation of sulfonamide resistance genes in arable soils due to repeated application of manure containing sulfadiazine. Applied and Environmental Microbiology 77, 2527-2530.

Hu, H.W., Han, X.M., Shi, X.Z., Wang, J.T., Han, L.L., Chen, D., He, J.Z., 2016. Temporal changes of antibiotic-resistance genes and bacterial communities in two contrasting soils treated with cattle manure. FEMS Microbiology Ecology 92.

Jechalke, S., Heuer, H., Siemens, J., Amelung, W., Smalla, K., 2014. Fate and effects of veterinary antibiotics in soil. Trends in Microbiology 22, 536-545.

Jiang, X.P., Morgan, J., Doyle, M.P., 2002. Fate of Escherichia coli O157 : H7 in manure-amended soil. Applied and Environmental Microbiology 68, 2605-2609.

Joy, S.R., Bartelt-Hunt, S.L., Snow, D.D., Gilley, J.E., Woodbury, B.L., Parker, D.B., Marx, D.B., Li, X., 2013. Fate and transport of antimicrobials and antimicrobial resistance genes in soil and runoff following land application of swine manure slurry. Environmental Science \& Technology 47, 12081-12088.

Karci, A., Balcioglu, I.A., 2009. Investigation of the tetracycline, sulfonamide, and fluoroquinolone antimicrobial compounds in animal manure and agricultural soils in Turkey. Science of the Total Environment 407, 4652-4664.

Kembel, S.W., Wu, M., Eisen, J.A., Green, J.L., 2012. Incorporating 16S gene copy number information improves estimates of microbial diversity and abundance. PLoS Computational Biology 8, e1002743.

Kemper, N., 2008. Veterinary antibiotics in the aquatic and terrestrial environment. Ecological Indicators 8, 1-13.

Kennedy, T.A., Naeem, S., Howe, K.M., Knops, J.M.H., Tilman, D., Reich, P., 2002 Biodiversity as a barrier to ecological invasion. Nature 417, 636-638.

Klappenbach, J.A., Saxman, P.R., Cole, J.R., Schmidt, T.M., 2001. rrndb: the ribosomal RNA operon copy number database. Nucleic Acids Research 29, 181-184.

Koike, S., Krapac, I.G., Oliver, H.D., Yannarell, A.C., Chee-Sanford, J.C., Aminov, R.L. Mackie, R.I., 2007. Monitoring and source tracking of tetracycline resistance genes in lagoons and groundwater adjacent to swine production facilities over a 
3-year period. Applied and Environmental Microbiology 73, 4813-4823.

Kolde, R., 2013. Pheatmap: Pretty Heatmaps. R package version 0.7.7. http://CRAN.Rproject.org/package $=$ pheatmap.

Kyselková, M., Kotrbová, L., Bhumibhamon, G., Chroňáková, A., Jirout, J., Vrchotová, N., Schmitt, H., Elhottová, D., 2015. Tetracycline resistance genes persist in soil amended with cattle feces independently from chlortetracycline selection pressure. Soil Biology and Biochemistry 81, 259-265.

Langille, M.G., Zaneveld, J., Caporaso, J.G., McDonald, D., Knights, D., Reyes, J.A. Clemente, J.C., Burkepile, D.E., Vega Thurber, R.L., Knight, R., Beiko, R.G., Huttenhower, C., 2013. Predictive functional profiling of microbial communities using $16 \mathrm{~S}$ rRNA marker gene sequences. Nature Biotechnology 31, 814-821.

Levine, J.M., 2000. Species diversity and biological invasions: relating local process to community pattern. Science 288, 852-854.

Li, B., Yang, Y., Ma, L.P., Ju, F., Guo, F., Tiedje, J.M., Zhang, T., 2015. Metagenomic and network analysis reveal wide distribution and co-occurrence of environmental antibiotic resistance genes. The ISME Journal 9, 2490-2502.

Ling, N., Zhu, C., Xue, C., Chen, H., Duan, Y., Peng, C., Guo, S., Shen, Q., 2016. Insight into how organic amendments can shape the soil microbiome in long-term field experiments as revealed by network analysis. Soil Biology and Biochemistry 99, 137-149.

Liu, R., Hu, H.W., Suter, H., Hayden, H.L., He, J.Z., Mele, P., Chen, D.L., 2016. Nitrification is a primary driver of nitrous oxide production in laboratory microcosms from different land-use soils. Frontiers in Microbiology 7.

Marti, R., Scott, A., Tien, Y.C., Murray, R., Sabourin, L., Zhang, Y., Topp, E., 2013. Impact of manure fertilization on the abundance of antibiotic-resistant bacteria and frequency of detection of antibiotic resistance genes in soil and on vegetables at harvest. Applied and Environmental Microbiology 79, 5701-5709.

McDonald, D., Price, M.N., Goodrich, J., Nawrocki, E.P., DeSantis, T.Z., Probst, A., Andersen, G.L., Knight, R., Hugenholtz, P., 2012. An improved Greengenes taxonomy with explicit ranks for ecological and evolutionary analyses of bacteria and archaea. The ISME Journal 6, 610-618.

McKenney, E.A., Williamson, L., Yoder, A.D., Rawls, J.F., Bilbo, S.D., Parker, W., 2015. Alteration of the rat cecal microbiome during colonization with the helminth Hymenolepis diminuta. Gut Microbes 6, 182-193.

Oksanen, J., Blanchet, F.G., Kindt, R., Legendre, P., Minchin, P.R., O'Hara, R.B., Simpson, G.L., Solymos, P., Steven, M.H.H., Wagner, H., 2014. Vegan: Community Ecology Package. $\mathrm{R}$ package version 2.2-0. http://CRAN.R-project.org/ package = vegan.

Ouyang, W.Y., Huang, F.Y., Zhao, Y., Li, H., Su, J.Q., 2015. Increased levels of antibiotic resistance in urban stream of Jiulongjiang River, China. Applied Microbiology and Biotechnology 99, 5697-5707.

Pakpour, S., Jabaji, S., Chenier, M.R., 2012. Frequency of antibiotic resistance in a swine facility 2.5 years after a ban on antibiotics. Microbial Ecology 63, 41-50.

Pallecchi, L., Bartoloni, A., Paradisi, F., Rossolini, G.M., 2008. Antibiotic resistance in the absence of antimicrobial use: mechanisms and implications. Expert Review of Anti-infective Therapy 6, 725-732.

Parham, J.A., Deng, S.P., Da, H.N., Sun, H.Y., Raun, W.R., 2003. Long-term cattle manure application in soil. II. Effect on soil microbial populations and community structure. Biology and Fertility of Soils 38, 209-215.

Philippot, L., Spor, A., Henault, C., Bru, D., Bizouard, F., Jones, C.M., Sarr, A. Maron, P.A., 2013. Loss in microbial diversity affects nitrogen cycling in soil. The ISME Journal 7, 1609-1619.

Pruden, A., Pei, R., Storteboom, H., Carlson, K.H., 2006. Antibiotic resistance genes as emerging contaminants: studies in Northern Colorado. Environmental Science \& Technology 40, 7445-7450.

Rahube, T.O., Marti, R., Scott, A., Tien, Y.C., Murray, R., Sabourin, L., Zhang, Y., Duenk, P., Lapen, D.R., Topp, E., 2014. Impact of fertilizing with raw or anaerobically digested sewage sludge on the abundance of antibiotic-resistant coliforms, antibiotic resistance genes, and pathogenic bacteria in soil and on vegetables at harvest. Applied and Environmental Microbiology 80, 6898-6907.

Rastogi, G., Sbodio, A., Tech, J.J., Suslow, T.V., Coaker, G.L., Leveau, J.H., 2012. Leaf microbiota in an agroecosystem: spatiotemporal variation in bacterial community composition on field-grown lettuce. The ISME Journal 6, 1812-1822.

RCoreTeam, 2014. A Language and Environment for Statistical Computing. R Foundation for Statistical Computing, Vienna, Austria. http://www.R-project. org.

Ronn, R., McCaig, A.E., Griffiths, B.S., Prosser, J.I., 2002. Impact of protozoan grazing on bacterial community structure in soil microcosms. Applied and Environmental Microbiology 68, 6094-6105.

Sarmah, A.K., Meyer, M.T., Boxall, A.B.A., 2006. A global perspective on the use, sales, exposure pathways, occurrence, fate and effects of veterinary antibiotics (VAs) in the environment. Chemosphere 65, 725-759.

Schmittgen, T.D., Livak, K.J., 2008. Analyzing real-time PCR data by the comparative C(T) method. Nature Protocols 3, 1101-1108.

Segata, N., Izard, J., Waldron, L., Gevers, D., Miropolsky, L., Garrett, W.S., Huttenhower, C., 2011. Metagenomic biomarker discovery and explanation. Genome Biology 12, R60.

Shannon, P., Markiel, A., Ozier, O., Baliga, N.S., Wang, J.T., Ramage, D., Amin, N., Schwikowski, B., Ideker, T., 2003. Cytoscape: a software environment for integrated models of biomolecular interaction networks. Genome Research 13, 2498-2504.

Su, J.Q., Wei, B., Ou-Yang, W.Y., Huang, F.Y., Zhao, Y., Xu, H.J., Zhu, Y.G., 2015. Antibiotic resistome and its association with bacterial communities during sewage sludge composting. Environmental Science \& Technology 49, 7356-7363.

Taft, D.H., Ambalavanan, N., Schibler, K.R., Yu, Z., Newburg, D.S., Ward, D.V., Morrow, A.L., 2014. Intestinal microbiota of preterm infants differ over time and between hospitals. Microbiome 2, 36.

Tang, X., Lou, C., Wang, S., Lu, Y., Liu, M., Hashmi, M.Z., Liang, X., Li, Z., Liao, Y., Qin, W., Fan, F., Xu, J., Brookes, P.C., 2015. Effects of long-term manure applications on the occurrence of antibiotics and antibiotic resistance genes (ARGs) in paddy soils: evidence from four field experiments in south of China. Soil Biology and Biochemistry 90, 179-187.

van Elsas, J.D., Chiurazzi, M., Mallon, C.A., Elhottova, D., Kristufek, V., Salles, J.F., 2012. Microbial diversity determines the invasion of soil by a bacterial pathogen. Proceedings of the National Academy of Sciences of the United States of America 109, 1159-1164.

van Elsas, J.D., Hill, P. Chronakova, A., Grekova, M., Topalova, Y., Elhottova, D. Kristufek, V., 2007. Survival of genetically marked Escherichia coli 0157:H7 in soil as affected by soil microbial community shifts. The ISME Journal 1 , 204-214.

Wang, L. Oda, Y. Grewal, S., Morrison, M., Michel Jr., F.C., Yu, Z., 2012. Persistence of resistance to erythromycin and tetracycline in swine manure during simulated composting and lagoon treatments. Microbial Ecology 63, 32-40.

Wertz, S., Degrange, V., Prosser, J.I., Poly, F., Commeaux, C., Freitag, T. Guillaumaud, N., Roux, X.L., 2006. Maintenance of soil functioning following erosion of microbial diversity. Environmental Microbiology 8, 2162-2169.

Wertz, S., Degrange, V., Prosser, J.I., Poly, F., Commeaux, C., Guillaumaud, N., Le Roux, X., 2007. Decline of soil microbial diversity does not influence the resistance and resilience of key soil microbial functional groups following a model disturbance. Environmental Microbiology 9, 2211-2219.

Xie, W.Y., Su, J.Q., Zhu, Y.G., 2015. Phyllosphere bacterial community of floating macrophytes in paddy soil environments as revealed by illumina highthroughput sequencing. Applied and Environmental Microbiology 81, 522-532.

Yan, Y., Kuramae, E.E., de Hollander, M., Klinkhamer, P.G., van Veen, J.A., 2017. Functional traits dominate the diversity-related selection of bacterial communities in the rhizosphere. The ISME Journal 11, 56-66.

Zhalnina, K., Dias, R., de Quadros, P.D., Davis-Richardson, A., Camargo, F.A., Clark, I.M., McGrath, S.P., Hirsch, P.R., Triplett, E.W., 2015. Soil pH determines microbial diversity and composition in the park grass experiment. Microbial Ecology 69, 395-406.

Zhen, Z., Liu, H.T., Wang, N., Guo, L.Y., Meng, J., Ding, N., Wu, G.L., Jiang, G.M., 2014. Effects of manure compost application on soil microbial community diversity and soil microenvironments in a temperate cropland in China. PloS One 9.

Zhou, Z., Raskin, L., Zilles, J.L., 2010. Effects of Swine manure on macrolide, lincosamide, and streptogramin B antimicrobial resistance in soils. Applied and Environmental Microbiology 76, 2218-2224.

Zhu, B., Chen, Q., Chen, S., Zhu, Y.G., 2017. Does organically produced lettuce harbor higher abundance of antibiotic resistance genes than conventionally produced? Environment International 98, 152-159.

Zhu, Y.G., Johnson, T.A., Su, J.-Q., Qiao, M., Guo, G.-X., Stedtfeld, R.D., Hashsham, S.A., Tiedje, J.M., 2013. Diverse and abundant antibiotic resistance genes in Chinese swine farms. Proceedings of the National Academy of Sciences of the United States of America 110, 3435-3440. 